\title{
Is JCSP Diverse Enough? Culturally Humble Strategies for Addressing Diversity, Equity, and Inclusion
}

\author{
Justine J. Reel \\ University of North Carolina Wilmington
}

This year, the Journal of Clinical Sport Psychology (JCSP) celebrates its 15th birthday! It is hard to grasp the innumerable changes to the journal over the past 3 years and how quickly my first term has whizzed by as editor-in-chief. The journal mission and author guidelines have been revised and in addition to original research papers, the journal now accepts practice papers, commentaries, and case study illustrations (Reel, 2018). Given the clinical and applied focus of our journal, the journal aims to better serve our applied audience's diverse needs both in the scope of published papers and style of the publications. It is our hope that JCSP's readership is finding papers to be easily digestible with clear evidence of clinical implications. We have expanded our editorial board to include members from different backgrounds and representing diverse institutions of higher education and clinical practices around the world. We have added an associate editor to meet the demands of the increasing volume of submissions. As we look ahead to the next several years, now is the time to make additional progress that will take the journal into the next decade. Our journal remains committed to addressing diversity, equity, and inclusion. The journal's mission can be found on the JCSP website and as follows:

The overall mission of the Journal of Clinical Sport Psychology (JCSP) is to disseminate scholarly, peer-reviewed work that integrates therapeutic strategies and performance enhancement approaches to best serve athletes, exercisers, and other performers. JCSP is designed to provide practical recommendations to mental health providers and applied sport psychology practitioners, stimulate provocative discussions, promote best practices and intervention strategies, and disseminate applied research findings.

Reel (2018, p. 1) included the following statement in reference to the journal's focus:

The Journal of Clinical Sport Psychology (JCSP) is a scholarly, peer-reviewed journal that provides practical and clinically relevant recommendations to 
mental health providers and practitioners in sport and exercise psychology, stimulates provocative discussions, promotes best practices and intervention strategies, and disseminates applied research findings that clearly show clinical relevance. The journal covers a broad range of topics. Some examples of relevant topics include, but are not limited to, psychology of injury, eating disorders, exercise and mental health, and substance use disorders. This journal highlights the clinical application of research findings within direct psychological service delivery spanning a wide range of clients and settings. JCSP recognizes the importance of diverse methodologies, varied treatment approaches, and the importance of having authors representative of a broad range of perspectives around sport and exercise psychology. JCSP is international in scope and submissions from around the world and with diverse populations are encouraged.

The journal has welcomed papers sharing divergent approaches for treating clients and designing studies along with diverse authorship. As editor-in-chief, it is one thing to state that diversity is valued but quite another to hold the journal accountable for inclusive excellence and creating social change. Cultural humility, which has been distinguished from cultural competence, emphasizes the need to constantly examine and reflect on how efforts to address diversity, equity, and inclusion are succeeding in the fight toward social justice (Fisher, 2019). The key feature of cultural humility is recognizing that we are always learning and progressing. Being culturally humble means that our journal needs to continue to listen, learn, and evaluate with the understanding that the work is never truly complete.

The challenge becomes how to actualize the goal of publishing diverse works and illuminating inclusive voices as JCSP's acceptance rate drops below $25 \%$. The dilemma is that as the quality of a journal improves by standard metrics (e.g., higher impact factor, lower acceptance rate), the likely outcome could be that fewer authors are able to contribute, resulting in published papers becoming less rather than more inclusive. Therefore, our editorial board has strongly recognized the need to be intentional in celebrating and promoting diversity, equity, and inclusion. Some of our initial strategies are outlined here. We welcome additional thoughts and ideas as well as your future participation in the journal.

\section{What Strategies Will JCSP Use for Advancing Diversity, Equity, and Inclusion?}

(a) Formation of a Special issue on Embracing and Living Intersectionality. $J C S P$ has supported the development of a call for papers that address intersectionality in sport, physical activity, and performance to be accepted for submission until June 2021: https://journals.humankinetics.com/ fileasset/JCSP/JCSP_CFP_Intersectionality.pdf. These papers are expected to be published in one or two issues in 2022. Although these special issues are a way to spotlight multiple identities and associated oppression, our editorial board recognizes that diversity, equity, and inclusion should be a common thread throughout all issues, not "just a special one." 
(b) Addition of a new "Around the World" section of the journal. Beginning in this issue (March 2021), you will notice a new section of works that includes papers from authors or populations from around the world. These papers will be open access to receive some additional attention and increased visibility. It is our hope that each journal issue will be able to include at least one paper that represents global activity in clinical sport psychology.

(c) Diversification of our editorial board. We would like to identify, nominate, and select editorial board members who represent diverse experiences. If you are interested in being a reviewer or possibly serving on the JCSP editorial board in the future, please contact me at JCSP@hkusa.com.

(d) Invitation of recommendations from our special issue co-editors, editorial board, and readership about how the journal can continue to address diversity, equity, and inclusion.

\section{References}

Fisher, E. (2019). Cultural humility as a form of social justice: Promising practices for global school psychology training. School Psychology International, 41(1), 53-66. doi:10. 1177/0143034319893097

Reel, J.J. (2018). Is JCSP the right fit? Tips for the successful preparation of manuscripts. Journal of Clinical Sport Psychology, 12(1), 1-3. doi:10.1123/jcsp.2018-0006 